\title{
Bi-modal deformation styles in confined mass-transport deposits: Examples from a salt minibasin in SE Brazil
}

\author{
Davide Gamboa ${ }^{1}$, Tiago M. Alves ${ }^{2 *}$
}

1: British Geological Survey, Columbus House, Tongwynlais, Cardiff, CF15 7NE, United Kingdom

2: 3D Seismic Lab, School of Earth and Ocean Sciences, Cardiff University, Main Building, Park Place, Cardiff, CF10 2AT, United Kingdom

*Corresponding author: alvest@cardiff.ac.uk

\begin{abstract}
High-quality 3D seismic data reveal bi-modal deformation styles in mass-transport deposits filling a salt minibasin in SE Brazil (Espírito Santo Basin). We analyse three mass-transport deposits within the same Miocene stratigraphic interval, and four other in Holocene strata. Our interpretation reveals that deformation in the mass-transport deposits relates to their long-axis orientation. As a result, masstransport deposits are divided in two types: a) Type 1 have long axes parallel to the direction of movement and show significant internal deformation; b) Type 2 have long axes perpendicular to the direction of movement, are highly heterogeneous and include large undeformed slabs. The long axes of Type 2 mass-transport deposits are parallel to the strike of bounding faults and salt structures. The majority of mass-transport deposits show intense deformation at their headwalls, and relative short remobilisation distances are inferred for both Types 1 and 2. In the study area, the timing of emplacement of mass-transport deposits was controlled by the growth of adjacent salt ridges. Earlier halokinesis in the northern axial areas of the minibasin shifted southwards in a second stage. In contrast, Holocene mass-transport deposits suggest alternating growth of the eastern and western salt ridges. Our results show that detailed seismic-stratigraphic analyses are key to understand the timings
\end{abstract}


and magnitude of deformation of mass-transport deposits in salt minibasins. The classification proposed can be applied to MTDs on continental margins and in lacustrine settings.

Keywords: Continental margins; SE Brazil; Salt diapirs; Mass-transport deposits; Minibasins; Halokinesis.

\section{Introduction}

Mass-Transport Deposits (MTDs) reflect one of the key processes shaping continental margins around the world, and are capable of transferring large masses of sediment from proximal to distal slope domains (Hampton et al., 1996; Masson et al., 2006; Li et al., 2015). Long-term trigger mechanisms for MTDs include processes such as sediment loading, fluid overpressure, the presence of weak layers, or increasing slope gradients with time. Short-term triggers comprise phenomena such as earthquakes, tectonic oversteepening, gas seepage, hydrate dissociation, volcanic event, halokinesis or sea-level changes (Lee, 2009; Masson et al., 2006; Posamentier and Martinsen, 2011; Sultan et al., 2004).

The emplacement of MTDs involves the remobilisation of material from headwall regions along a basal interval, and records a continuum of deformation styles along their transport direction(s) (Alves and Lourenço, 2010; Bull et al., 2009; Butler and McCaffrey, 2010; Ogata et al., 2014; Tripsanas et al., 2008). As a result, extensional structures are often observed near the headwalls of MTDs, and change downslope into a transitional domain revealing increasing strata disaggregation (Bull et al., 2009). This variation in deformation styles is often followed downslope by: a) the generation of compressional toe domains characterised by thrusting and folding of strata, or b) complete disaggregation of the remobilised material (Frey-Martinez et al., 2005). Deformation styles thus change spatially and depend on controls such as sediment cohesion and the run-out distance recorded by discrete MTDs. As a result, MTDs can be highly heterogeneous, comprising variable proportions 
of blocks and slump folds amidst a matrix of debrites (Bull et al., 2009; Hampton et al., 2006; Masson et al., 2006; Posamentier and Martinsen, 2011).

The proliferation of 3D seismic data has led to complex analyses of MTDs' internal deformation and remobilisation processes in large areas of continental margins (Bull et al., 2009; Gee et al., 2006; Moscardelli and Wood, 2008; Omosanya and Alves, 2013b; Posamentier and Martinsen, 2011). Such a plethora of information resulted, in a first stage, in classifications of MTDs based on their frontal geometry. They were classified as frontally confined slides when fully buttressed against a frontal ramp, and frontally emergent where the remobilised mass is able to flow beyond a frontal confinement (Frey-Martínez et al., 2006). In parallel, the interpretation of large 3D seismic datasets from offshore Trinidad and Tobago allowed the classification of MTDs in slope-attached, shelf-attached, and locally detached systems, the latter of which record mass-wasting deposits that do not link with proximal domains of continental margins (Moscardelli and Wood, 2008).

In the particular case of salt-rich basins, halokinesis often controls the onset and geometry of masstransport deposits (Giles and Rowan, 2012; Jackson et al., 1994). In salt-rich basins, strata deposited over growing salt structures are either thinned or completely removed by erosional processes, and can accumulate as MTDs in peripheral salt-withdrawal basins, or minibasins (Gamboa et al., 2011; Giles and Lawton, 2002; Tripsanas et al., 2004). Detached MTDs thus predominate over far-reaching slope-attached MTDs in distal minibasins of the Gulf of Mexico, Brazil and West Africa, leading to the deposition of heterogeneous strata that can be tied to key periods of salt movement (Beaubouef and Abreu, 2010; Jackson, 2012; Madof et al., 2009; Olafiranye et al., 2013).

This work investigates Miocene and Holocene MTDs occurring in minibasins of the Espírito Santo Basin, SE Brazil (Fig. 1). It presents a detailed description of a) three Miocene MTDs bounded by correlative stratigraphic surfaces, and b) four Holocene MTDs on the seafloor. We present detailed maps of the top and base surfaces of the seven (7) MTDs, complemented by thickness and amplitude maps, variance data and gradient profiles, so we assess their internal heterogeneity. In the discussion we compare the internal character and degree of deformation of two distinct types of MTDs, and how 
they can be used as markers for local halokinetic movements. In this paper, submarine slide blocks consist of semi-preserved strata that are named as 'rafted' if remobilised to any degree within or beyond the toe of the MTD, or 'remnant' if they are kept in situ and form isolated volumes of strata in vertical stratigraphic continuity with underlying non-MTD units (Alves, 2015; Bull et al., 2009; Frey-Martinez et al., 2005). Rafted blocks comprise a spectrum of morphologies, in which slide slabs are included. These slide slabs form tabular masses of hundreds to thousands of metres in length and tens of metres in height, thus having very low thickness-to-length ratios (O'Leary, 1991; Varnes, 1978).

\section{Geological Setting}

\subsection{Espírito Santo Basin}

The Espírito Santo Basin is the northernmost of a series of Mesozoic rift basins located in SE Brazil (Davison, 2007; Fiduk et al., 2004) (Fig. 1). After the rift and transitional stages, the latter of which records the deposition of thick evaporitic units within a restricted basin, a two-phase drift stage dominated the Late Cretaceous to Cenozoic evolution of SE Brazil (Figs. 1c and 2) (Fiduk et al., 2004; Mohriak, 2003). The early drift stage records the accumulation of Albian carbonate platforms underneath Upper Cretaceous-Paleogene mudstones, and marks a phase of relative deepening of the Espírito Santo Basin. The transition to the late drift stage (Lower Eocene) coincides with the onset of a marine regressive megasequence. This stage led to the deposition of a thick prograding sequence on the entire continental slope of SE Brazil (Davison, 2007; Demercian et al., 1993; Mohriak, 2003; Moreira and Carminatti, 2004).

Several erosive episodes took place in the Espírito Santo Basin during the drift stage, and resulted in the development of eleven (11) unconformities associated with discrete episodes of submarine channel incision (Fiduk et al., 2004; França et al., 2007) (Fig. 1c). In parallel to submarine channel 
incision, recurrent mass-wasting events led to the deposition of thick and laterally continuous MTDs in proximal and mid-slope parts of Espírito Santo (Fig. 2) (Gamboa et al., 2010; Omosanya and Alves, 2013a).

Salt tectonics has a close relationship with the sedimentary evolution of SE Brazil. Thin-skinned extension of Cenozoic strata above Aptian evaporites led to development of an array of salt-related structures in the study area (Fig. 2). Thin-skinned extension culminated in a Late Cenozoic peak in halokinesis, which was associated with an increase in sediment input reaching the continental slope of Espírito Santo (Fiduk et al., 2004). At the same time, salt structures seem to have exerted a major control on the geometry of the sedimentary pathways and associated deposits across the continental slope (Love et al., 2005).

\subsection{Local geological setting}

Extensional faults occur in proximal areas of the Espírito Santo Basin with thin Aptian salt, and are followed downslope by a wide area with salt diapirs, part of a mid-slope transitional domain (Fig. 2). Allochthonous salt walls and canopies occur in the distal compressional domain (Davison, 2007; Demercian et al., 1993; Fiduk et al., 2004; Mohriak, 1995). Recent salt growth episodes also led to marked deformation of the modern seafloor (Fiduk et al., 2004) (Fig. 1b and 2).

The region interpreted in this paper is located in the distal domain of the Espírito Santo Basin, where salt-withdrawal minibasins developed due to the growth of allochthonous salt structures (Fig. 1 and 2). The studied minibasin follows a N-S orientation and is bounded by N-striking salt ridges (R1 and R2) to the west and east (Fig. 1b and 3). Water depth ranges from $2000 \mathrm{~m}$ on the crest of R1 to 2330 $\mathrm{m}$ in the axis of the main minibasin. Fault distribution is not uniform in the study area and results from spatially variable interactions between the R1 and R2 salt ridges and deeper structures (Fig. 3b). Hence, a high number of closely spaced faults is observed to the north, showing orientations sub- 
perpendicular to the salt ridges (Fig. 3c). Faults are scarcer towards the central and southern areas of the minibasin, and only observed close to the high-curvature segment of ridge R1 (Fig. 4c).

Two main Cenozoic stratigraphic units are identified on 3D seismic data (Fig. 3). The shallower unit is interpreted to be Miocene to Holocene in age, and shows low- to moderate-amplitude seismic reflections with good lateral continuity. Chaotic strata in this interval reveal the presence of MTDs (Fig. 3a and 3b). The deeper stratigraphic unit in the minibasin is Eocene to Oligocene in age, being characterised by moderate- to high-amplitude internal reflections. Reflection continuity is variable, and is often interrupted by MTDs with low to moderate amplitude, chaotic reflections (Fig. 3a).

\section{Data and Methods}

The interpreted 3D seismic volume covers an area of $\sim 276 \mathrm{~km}^{2}$ on the distal continental slope of the Espírito Santo Basin (Fig. 1). Data acquisition used a dual airgun array and six 5700 m-long streamers. Seismic signal was sampled at $2 \mathrm{~ms}$ and zero-phased migrated with a $12.5 \mathrm{~m}$ grid line spacing (inline and crossline).

In addition to the seafloor, four continuous horizons (H1 to $\mathrm{H} 4$ ) where mapped within the minibasin (Fig. 3). Horizons $\mathrm{H} 1$ and $\mathrm{H} 4$ delimit the interval of occurrence of the Miocene MTDs (Fig. 3). Horizon H1 underlies the Miocene MTDs, below which the seismic reflections are relatively undisturbed. Horizon $\mathrm{H} 4$ is interpreted as the youngest surface presenting deformation associated with the Miocene MTDs, i.e. the shape of the seafloor immediately after their emplacement.

Seismic attributes of interest to our analysis included RMS (root-mean square) amplitude and variance slices. Variance slices were extracted from a volume flattened at H1 (Fig. 3), allowing for the assessment of the MTDs’ internal geometry at equal time intervals above and below their basal surfaces (Fig. 4b and 4c).

In this paper, MTDs were characterised based on their morphometrics and relative thickness. We opted for parameters such as the length of 'long' and 'short' axes, instead of length and width of the 
deposit, to characterise the dimensions of what is a series of elongated MTDs on map view (Fig. 4). As a result, any reference to length or run-out distance(s) relate, in this work, to a quantitative parameter that is parallel to the direction of transport of an MTD, with width being perpendicular to this latter (Moernaut and De Batist, 2011; Moscardelli and Wood, 2015; Varnes, 1978).

To help our analysis, the 3D seismic volume was depth-converted for the Miocene-Holocene interval of interest using an estimated seismic velocity of $1500 \mathrm{~m} / \mathrm{s}$ for the water column and 1800 m/s for buried strata, based on velocity data at DSDP Site 516 (Barker et al., 1983). The latter p-wave velocities and the dominant frequency of $40 \mathrm{~Hz}$ of the seismic volume indicate a vertical resolution of $10 \mathrm{~m}$ at the depth of the interpreted MTDs. The horizontal resolution approaches $12.5 \mathrm{~m}$, a value equivalent to the gridline spacing of the seismic volume.

\section{Description of MTDs in the distal Espírito Santo Basin}

Thickness maps were computed for the stratigraphic interval spanning H1 to H4 (Fig. 4a). Three MTDs, named MTD A, B and C, were interpreted within this stratigraphic interval (Figs. 3 and 4). These deposits share a common base horizon along H1 (Fig. 3), and their occurrence led to localised thickening of strata within the axis of the studied minibasin (Fig. 4a).

\subsection{MTD A}

Mass-transport deposit A occurs on the axis of the salt minibasin and is bounded by H1 and H3 (Fig. 5). It shows continuous internal reflections with moderate amplitude (Fig. 5a, 5b and 5c). MTD A shows a SW-trending long axis, parallel to its run-out direction. Its long and short axes have $4772 \mathrm{~m}$ and $2900 \mathrm{~m}$, respectively, and the deposit shows a volume of $0.34 \mathrm{~km}^{3}$ within an area of $13.3 \mathrm{~km}^{2}$ (Fig. 6).

The base of MTD A (horizon H1) shows a stepped morphology associated with sets of WNWtrending faults (Fig. 5a and 6a). The steeper angles in horizon $\mathrm{H} 1$ range between $7^{\circ}$ and $17^{\circ}$ over the 
faults, whereas its flattest areas do not exceed $2^{\circ}$ (Fig. 6a). The top surface of MTD A (H3) mimics the morphology of H1, but presents relatively smooth slope breaks and several curved ridges (Figs. 5a, 5d and 6a). Its steeper part is located towards the north and shows local erosional scarps (Fig. 6a). A sharp irregularity in H3 is observed above a small horst structure (Fig. 5a).

Mass-transport Deposit A comprises an extensional domain to the north, with two main faults defining a headwall scarp with generally straight segments (Fig. 5a, 5d and 6c). Disaggregated facies extend northwards of the fault scarps and suggest the presence of local retrogressive failures (Fig. 5a and 5d). The thinnest MTD strata in the headwall domain reveal important remobilisation upslope (Fig. 6b).

Thickness data for MTD A shows a heterogeneous accumulation of sediment (Fig. 6b). The thickest accumulations reach $\sim 45 \mathrm{~m}$ in the southeastern part of the toe domain. Other WNW-trending patches reach $30 \mathrm{~m}$ in the middle of MTD A (Fig. 6b), with the thinnest accumulations ( $10 \mathrm{~m}$ thick) being adjacent to E-W headwall faults. Such variability in thickness reflects a marked zonation in MTD A, in which well-delimited boundaries are bounded by underlying faults (Fig. 5a).

Variance slices crossing MTD A also suggest heterogeneous deformation in the form of alternating arcuate ridges and low-variance patches (Fig. 6c). In general, ridges verging in a downslope direction sign the presence of compressional structures, whereas planar features dipping in the same direction of the slope reflect the presence of extensional faults (Fig. 5a and 5b). Furthermore, compressional ridges show relatively higher continuity on seismic attribute maps, whereas extensional faults show shorter segments (Fig. 6c).

Root-Mean Square (RMS) amplitude maps further highlight this internal heterogeneity by showing curved ridges as alternations of high- and low- amplitude reflections (Fig. 6d). Ridges are associated with thickness variations in MTD A, and mark variations in the degree of remobilisation of strata in distinct parts of the deposit. Thus, localised compression at the centre of MTD A is followed downslope by an extensional domain with multiple normal faults, akin to a secondary headwall region (Fig. 5a, 5b, 6c). This extensional domain changes downslope into the toe of MTD A, where two sets 
of compressional ridges are identified: a) a main SSW-verging set of ridges in strata that is 20 to 35 m thick, and b) a secondary set located on the southwest part of MTD A (Figs 5d, 6b and 6c). Ridges in this latter region verge to the west, showing higher curvature and shorter spacing (Fig. 6c and 6d).

Kinematic indicators in MTD A show the bulk of its movement to have followed a SSW direction, but with variable confinement at its toe depending on pre-existing faults (Fig. 5d). This character resulted in a progressively emergent front, and a $50^{\circ}$ westward shift of the flow, due to a decrease in fault throw underneath MTD A (Figs.5d and 6c).

\subsection{MTD B}

In the study area, MTD B is also bounded by horizons H1 and H4 (Fig. 7a). It shows an identical value of $\sim 2500 \mathrm{~m}$ for its long and short axes, covering an area of $6.4 \mathrm{~km}^{2}$ for a volume of $0.4 \mathrm{~km}^{3}$. The source area of MTD B is located on the SW flank of salt ridge R2, and the deposit thickens towards its toe area to a maximum of $80 \mathrm{~m}$ (Figs. 7a and 7d). In addition, localised thickening is observed in a 350 m-wide erosional slot located upslope (Fig. 7a and 7c). The angle of horizon H1 reaches $8^{\circ}$ over the steeper flank of the salt ridge, but decrease to $1.3^{\circ}$ towards the west (Fig. 6a). Locally, H1 shows multiple steps dipping towards the flank of R2, which are coincident with the frontal ramp of the erosive slot (Fig. 7a). The lack of a headwall scarp in MTD B is likely a result of post-failure halokinesis.

A seismic profile along the long axis of MTD B shows low amplitude and disrupted reflections near its upper part (Fig. 7a). However, variance slices reveal arcuate features (associated with extensional faults) within the general mottled character of the headwall area (Fig. 7d). Reflection continuity increases downslope, becoming identical to non-remobilised strata at the toe of the MTD (Fig. 7a). Elongated ridges cross the full width of MTD B, and show a regular spacing of $50 \mathrm{~m}$ to $60 \mathrm{~m}$ (Fig. 7d and 7e). The ridges record compression at the front of MTD B, as they are associated with imbricated west-facing thrusts (Fig. 7a). The frontal ramp of MTD B is not bounded by any major fault (Fig. 7a). 


\subsection{MTD C}

Mass-transport Deposit C occurs on the flank of salt ridge R1 (Figs. 8 and 9). Its NE-trending long axis reaches $11100 \mathrm{~m}$, and is parallel to the orientation of ridge R1 (Fig. 9a). Its short axis approaches $4500 \mathrm{~m}$ for a volume of remobilised material of $\sim 2.60 \mathrm{~km}^{3}$ i.e., six to eight times larger than MTDs A and B. MTD C covers an area of $41 \mathrm{~km}^{2}$. Importantly, the orientation of its long axis is perpendicular to its run-out direction (Fig. 8 and 9).

The thickness of MTD C increases eastwards, with the thinnest strata occurring along its headwall (Fig. 9c). The thickest accumulations range between $70 \mathrm{~m}$ and $90 \mathrm{~m}$ along its elongated toe area, near the axis of the minibasin. Large portions of strata in the middle part of MTD C show uniform thickness (Figs. 8 and 9a), due to the presence of slabs (sensu O'Leary, 1991) in MTD C. These slabs are flat and relatively thin (60-70 m-thick) when compared to their length and width. Due to their minor internal deformation, the slabs show low variance (Fig. 9d) and good reflection continuity, in similarity to non-remobilised strata in other parts of the slope (Figs. 8 and 9d).

Variations in the dip angle of $\mathrm{H} 1$ and $\mathrm{H} 4$ are associated with changes in the heterogeneity of MTD C. Extensional domains upslope show a general angle of $3.7^{\circ}$ along H1, but local features can reach $15^{\circ}$ to $20^{\circ}$ (Fig. 9b). At the middle part of MTD C, horizon H1 shows an angle of $\sim 3^{\circ}$, decreasing downslope to approximately $1^{\circ}$. The top of MTD C shows angles of $\sim 3^{\circ}$ in its upper part, and is marked by irregularities associated with sediment remobilisation. The top of the slabs shows smooth surfaces dipping $2^{\circ}$ to $2.5^{\circ}$, followed downslope by angles $<1^{\circ}$ where the compressional ridges are observed (Fig. 9b).

The complex morphology of the top surface of MTD C (H4) highlights three different domains. Rugged patterns are observed in its headwall and toe due to internal folding and faulting during sediment remobilisation (Fig. 8b, 8c, 9a). Curved faults, possibly associated with regressive slope failures (Galloway, 1998), occur adjacent to longer linear faults in the headwall domain. 
Within the upslope domain, closely spaced extensional faults are present near the inferred scarps (e.g. Fig. 8c), whereas thrust faults can develop towards the east, adjacently to the western flanks of the MTD slabs (Fig. 8b). Elongated ridges, spaced between $90 \mathrm{~m}$ and $100 \mathrm{~m}$, are observed in the toe domain, eastwards of the slabs (Fig. 8b, 8d, 9d, 9e). Significantly, toe ridges are bound by east- and west-dipping faults, with continuous seismic reflections occurring within the fault-bounded blocks (Fig. 8b and 8d). These compressional structures define a series of wedge-shaped pop-up blocks of cohesive strata along the toe of MTD C, which contrast with the disaggregated facies and imbricated toe thrusts of published MTD models (e.g. Frey-Martinez et al., 2005). The majority of the compressional ridges are oriented N-S, but sub-perpendicular W-E segments of limited extent are also observed (Fig. 9d).

Based on the interpretation of local kinematic indicators, MTD C denotes an eastward movement along the steeper flanks of salt ridge R1, with strata remobilised as far as the low-gradient axis of the salt minibasin (Fig. 4a). The salt ridge and associated faults play a role in delimiting the MTD's headwall (Fig. 8 and 9d). However, the presence of scalloped scarps suggest the presence of a complex headwall in MTD C, and the occurrence of localised retrogressive failure events that were not strictly delimited by faults related to the salt structures (Fig. 8b and 9d).

\subsection{Seafloor MTDs}

Several seafloor MTDs are observed in the study area (Fig. 10 and 11). The roughness of the seafloor maps shows the great majority of these Holocene MTDs to be close to structural highs created by salt ridges, and over MTDs B and C. In addition, small failure events and arcuate faults are observed over MTD A in the axial areas of the salt minibasin (Fig. 1b). Four seafloor MTDs are described in this section (SF1 to SF4), and compared with the Miocene MTDs A to C.

The first of the Holocene MTDs, SF1, occurs on the western flank of ridge R1 (Fig. 10b). It shows a long axis of $2380 \mathrm{~m}$ striking parallel to the salt ridge, and a short axis of $1280 \mathrm{~m}$ parallel to its runout direction (Fig. 10a and 10c). Remobilised strata in its upper domain range between 32 and 45 m 
in thickness, and are delimited to the east by a scalloped headwall with extensional faults (Fig. 10a, 10c and 10d). Two rotated blocks $\sim 60$ m-thick and $~ 500$ m-long occur close to the headwall and show very moderate remobilisation (Fig. 10a).

Elongated slabs parallel to the long axis of SF1 are present in the middle part of the MTD, and show smooth top surfaces and a relatively uniform thickness of $45 \mathrm{~m}$ (Fig. 10a and 10d). In contrast, the toe domain of the deposit is up to 59 m thick, where elongated compressional ridges develop along the full width of SF1 (Fig. 10d). These characteristics are in all identical to the morphology of MTD $\mathrm{C}$, and mirror the observed relationship between rugosity and gradient changes of the MTDs bounding surfaces (Fig. 10c).

Mass-transport Deposit SF2 is located on the eastern flank of ridge R1, being $4550 \mathrm{~m}$ long and 1930 m wide (Fig. 10b). Its long axis strikes to the SE i.e., roughly perpendicular to the salt ridge. Strata in the extensional domain has a thickness of $20 \mathrm{~m}$ to $35 \mathrm{~m}$ when confined by a frontal ramp, but they can be 85 m-thick in areas with imbricated thrusts of its compressional domain (Fig. 10b, 10e and 10f). In particular, an elongated thin deposit with up to $25 \mathrm{~m}$ in thickness is observed at the front of SF2 (Fig. 10b and 10e), resulting from an emergent flow that extends $2400 \mathrm{~m}$ beyond the bulk of SF2. These morphological trends are identical to MTDs A and B (Figs. 4 and 5).

Still on the flank of ridge R1, MTD SF3 occurs 1800 m southwest of SF2 (Fig. 10b). This MTD is $3140 \mathrm{~m}$ and $1520 \mathrm{~m}$ along its long and short axes, respectively, being delimited by a arcuate headwall scarp to the west (Fig. 10b and 10g). Two locations with strata pinch-outs, where thickness does not exceed $25 \mathrm{~m}$, occur in the evacuation area adjacent to the scarp. These two locations are followed downslope by strata $\sim 65$ m-thick that are $\sim 1200$ m away from the headwall scarps (Fig. 10h). An elongated deposit, up to $25 \mathrm{~m}$ in thickness, extends 2000 m further downslope along a $200 \mathrm{~m}$ and 500 m-wide area beyond the main SF3 body (Fig. 10g and 10h).

Seismic profiles show characteristic mottled reflections within the main body of SF3, whereas elongate deposits from the emergent front are represented by continuous reflections with subtle 
irregularities and amplitude variations. These spatial variations in reflection character support the presence of thin remobilised strata in SF3, despite its similar aspect to intact strata nearby (Fig. 8g).

The final MTD SF4 is located along ridge R2 and shows a run-out distance of $2000 \mathrm{~m}$ to $2500 \mathrm{~m}$ (Fig. 11). Although the long axis of the deposit is parallel to the strike of R2, discrete flows oriented perpendicularly to the ridge are interpreted to form SF4. A complex headwall scarp bounds SF4 to the east and to the north, along the ridge flank. The scarp limit is identified at depths of $\sim 2100 \mathrm{~m}$, although steeper scarps occur higher on R2 at depths of 2045 m (Fig. 11a). A remarkable feature of discrete slope failures occurring along R2 is the general lack of chaotic reflections below the seafloor

(Fig. 11b). Instead, evidence of strata deformation associated with SF4 is expressed by small-scale roughness along continuous reflections, similarly to the character of turbiditic or drape deposits (Fig. 11b). Thus, SF4 shows a relatively smooth top surface with limited relief on the seafloor. This can result from post-depositional reworking and sediment drape. However, the moderate subsurface deformation observed on seismic suggests that SF4 is associated with relatively thin, low volume flows with limited morphological expression on the seafloor (Fig. 11b).

\section{Quantitative analysis of MTDs}

Quantitative analyses show that MTDs A to C are the largest in the study area. Nevertheless, long/short axes ratios for all interpreted MTDs show similar ranges, regardless of their orientation, size and stratigraphic position (Fig. 12a). The lowest values were recorded for MTD B, with long/short axes ratios near one.

Comparisons between the area and volume of all MTDs indicate similar scale-relationships, despite their difference in size (Fig. 12c). Positive correlations were also observed between the area and volume of slabs in MTD C (Fig. 12d). The size of the large slabs in MTD C is also similar to the range in length and width of mass-transport blocks identified in slope-attached MTDs from the upper slope of Espírito Santo (Fig. 12e). This character suggests that similar scale-relationships occur in 
proximal and distal domains of continental margins, for distinct MTDs (see also Alves and Cartwright, 2009; Gamboa and Alves, 2015).

The headwall length of all interpreted MTDs show a positive correlation with both area and volume (Fig. 12f and 12g). Bar the larger deposit (MTD C), all data points in the headwall length-area plot fall close to the fitted trend line, and present a high correlation coefficient of 0.9 (Fig. 12f). Similarly, MTD volume also shows a positive correlation with headwall length, with a correlation coefficient of 0.85 (Fig. 12g).

The ratio between headwall length and its distance-to-toe was also calculated (Fig. 12h). The results show ratios $>1.0$ for MTDs C and SF1, which have long axes perpendicular to their run-out direction (Fig. 9 and 10a), whereas the remainder of MTDs show ratios $<1.0$ (Fig. 12h). The values and trends observed indicate close similarities in the geometry of the interpreted MTDs. However, care must be taken when analysing their relationships as the short number of samples (MTDs) used may limit their statistical significance.

\section{Discussion}

\subsection{Bi-modal MTD types in confined minibasins}

In the study area, the majority of MTDs show elongate morphologies typical of remobilised slope strata, regardless of their location within the salt minibasin (Figs 1 and 3). Apart from their overall size, in which buried MTDs are clearly larger (Fig. 12b), there is no clear difference in the long/short axes ratios of buried and seafloor MTDs (Fig. 12a). Furthermore, the MTDs in the salt minibasin show close relationships between their area and volume (Fig. 12c). These two parameters also correlate well with the length of the headwall area (Figs. $12 \mathrm{f}$ and $12 \mathrm{~g}$ ), similarly to trends observed in Klar et al. (2011), Micallef et al. (2008) or Moernaut and De Batist (2011).

A clear distinction between MTDs is observed when comparing the length of the headwall area to the measured distance-to-toe (Fig. 12h), which in this study is considered to be equivalent to the 
MTDs' length. The results show a bi-modal trend in the MTDs' headwall length/distance-to-toe ratios (Fig. 12h). Several deposits show ratios below or close to one, but MTDs C and SF2 show significantly higher values (Fig. 12h). We interpret these differences to be linked to the orientation of the long axes of the two MTDs when compared to their run-out direction, and internal deformation. Such contrasts are clear when comparing, for example, MTDs A and C (Figs. 3a, 5d and 9d).

Based on the ratios above, we can define two types of MTDs - Type 1 and Type 2 - according to their morphology. Type 1 MTDs are characterised by a headwall length/distance-to-toe ratio below one (1), meaning that the long axis of the deposit is sub-parallel to its length and the direction of movement (Fig. 13a). Type 2 MTDs are likely to be less common in salt minibasins, being characterised by long-axis orientations that are roughly perpendicular to their length and direction of movement (Fig. 9a and 10a). Type 2 MTDs show headwall length/run-out distance ratios above one (1). Type 2 MTDs are represented in the study area by MTDs C and SF1, which show very similar internal characters i.e., present slabs in a generally convergent, frontally confined flow. Other published examples of Type 2 MTDs have been observed around salt ridges in West Africa (Maia et al., 2015), in the Gulf of Mexico (Posamentier and Martinsen, 2011; Madof et al., 2009), and in lacustrine settings (Moernaut and de Batist, 2011).

Defining the type of MTD must take into account geomorphic trends and any spatial relationships between the mass flows that generated the deposit. In the study area, MTD SF4 can be used to exemplify this. Despite showing a (large) headwall length/run-out distance ratio characteristic of Type 2, SF4 is composed of multiple, and likely diachronous, ridge-perpendicular Type 1 flows (Fig. 11). Type 1 MTDs could also have similar geometry to Type 2 in flows diverted and entrenched along the axis of narrow confined basins. Identifying the length of the source area and comparing it to MTD run-out distance is therefore key to distinguish both types of MTDs. 


\subsection{Internal deformation in Types 1 and 2 MTDs}

Deformation styles in complex MTDs show a wide range of structures associated with: a) variable degrees of strata disaggregation, b) flow velocity, c) flow orientation, and d) remobilisation distances (Ashabranner et al., 2010; Gamboa et al., 2011). In general, there is a direct correlation between the degree of strata disaggregation, remobilisation distance and flow velocity (Posamentier and Martinsen, 2011; Nemec, 1991). Thus, the lower is the flow velocity, the higher is the potential to preserve intact strata in MTDs. Although the classic slope instability models tend to show an increasing deformation continuum from headwall to toe (e.g. Bull et al., 2009), such models are not fully applicable to some of the MTDs interpreted in this work, especially when deformation decreases with their run-out distance.

\subsubsection{Type 1}

Type 1 MTDs tend to have higher degrees of internal deformation and develop frontal domains with numerous imbricated thrusts and ridges (Fig. 13a), as exemplified by MTDs A, B, SF2 and SF3 (Figs. 5, 7 and 10). They thin towards their uppermost extensional domains and thicken in compressional areas regardless of their relative position within the MTD (i.e., at the toe or associated with lateral ramps). Frontal confinement is common in Type 1 MTDs, but relatively thin emergent sections of the flow can also occur (Fig. 13a). This variability in frontal confinement can be influenced by structures underlying the MTDs, as exemplified in MTD A (Fig. 5). Frontal ramps confined MTD A where the largest fault throws were sufficient to dissipate the energy of the flow (Fig. 5b), with relatively small fault offsets observed in its southwestern sector allowing the flow to emerge and run for $850 \mathrm{~m}$ beyond the main frontal fault (Fig. 5d). Thus, Type 1 MTDs not controlled by faults can have significantly longer emergent fronts, as exemplified in the study area by the seafloor MTDs (Fig. 11). The preferential occurrence of contractional faults and ridges in low gradient regions of the MTDs' basal intervals (Figs. 6a and 13a) suggests local dissipation of kinetic energy induced by a structurallycontrolled decrease in slope gradient - ultimately favouring the arrest and frontal confinement of the 
flow (Frey-Martínez et al., 2006; Moernaut and De Batist, 2011). Secondary extensional and contractional domains also occur, as exemplified at the middle part of MTD A, where internal deformation styles are associated with gradient variations along the stepped basal interval (Figs. 6a and 13a). Basal structures forced the buttressing and thickening of strata in the upper part of MTD A, and were followed by extension and possibly flow acceleration at its downslope flank - similarly to deformation in the Tampen Slide (Gafeira et al., 2010).

\subsubsection{Type 2}

Type 2 MTDs are exemplified by MTDs C and SF1, which show clear contrasts in deformation (Figs. 9, 10a and 13b). A common aspect in both MTDs is the presence of slabs with uniform thickness at their translational domains. These slabs separate evacuation domains upslope from compressional ridges formed at the toe of the MTDs (Figs. 8, 9d and 13b). A key characteristic of these slabs is their size and (intact) aspect on the seismic data, particularly in MTD C (Figs. 8 and 9). They are apparently continuous with underlying in situ strata, a property more commonly associated with remnant blocks (Alves, 2015; Gamboa et al., 2011). Intra-slab shearing processes are also rarely identifiable on 3D seismic data, with slabs considered to have moved as 'frozen' masses. However, small intra-slab thrusts in MTD C detached at the base of horizon H3 (Fig. 8e and 13b), may represent internal bed-parallel shearing. This phenomena is prone to occur in slabs sharing similar seismic characters, even when the deformation is not fully resolvable on seismic data. There is the possibility that MTDs C and SF1 represent an extreme case of internal strata preservation, and increased faulting and/or strata disaggregation may, therefore, occur in the translational domains of more dynamic Type

\section{MTDs.}

Enhanced deformation in the upper part of Type 2 MTDs is likely related to the steeper slope angles around the salt ridges, which induced higher flow velocities in the evacuation area and favoured strata disaggregation. Considering a synchronous movement in all elements of Type 2 MTDs, contrasts in internal remobilisation velocity can develop secondary compression zones between the evacuation 
and translation domains in response to the buttressing of the faster headwall strata against adjacent slow-moving slabs (Fig. 13b). In addition, recurrent failure events near the headwall also have the potential to aid the movement of the large slabs (Kvalstad et al., 2005, Ogata et al., 2014), or to enhance local buttressing if the slabs have stopped moving.

Localised ridges parallel to the direction of movement were observed in Type 2 MTDs, suggesting that secondary internal stresses were generated during strata remobilisation (Fig. 6f, 7b and 13b). These stresses can be influenced by underlying faults, as in MTD C (Fig. 6a), or by softer deforming strata confined between moving slabs. The long ridges at the toe result from relatively uniform compression that was controlled by the slow movement of slabs (Fig. 6f). While the upslope strata of Type 2 MTDs could have had variable remobilisation distances, at the central and toe domains of the deposit the remobilisation distance is considered to be comparatively smaller, reflecting slower flow velocities due to the high degree of strata preservation (Posamentier and Martinsen, 2011). Slab movement in MTD C was in the order of $50 \mathrm{~m}$ to $70 \mathrm{~m}$, as estimated from the restauration of pop-up blocks at its toe (Fig. 8). Such short remobilisations and the presence of pop-up blocks - which contrast with the imbricated toe thrusts of faster flows - suggest low-rate, progressive compression of strata at the toe of MTD C induced by the slow movement of slabs (Fig. 13b).

\subsubsection{Factors influencing Type 1 and Type 2 MTDs}

Local triggers of slope failure can be varied, consisting of tectonic movements, the presence of weak overpressured shales or gas hydrate dissociation, to name a few (Hampton et al., 1996; Masson et al., 2006; Posamentier and Martinsen, 2011). These are likely to generate either Type 1 or 2 MTDs, as both types occur in stratigraphic units of uniform seismic character in the studied minibasin. Furthermore, the deposits studied here are likely to have identical trigger mechanisms and low remobilisation distances due to local structural controls on the flows. Short remobilisation distances are also supported by the relative position of the studied MTDs, which occur on ridge flanks and in 
specific locations in the salt-withdrawal basin, in contrast to the remobilised deposits that pond at the centre of the minibasins (Madof et al., 2009).

The main factor leading to the generation of Type 1 or Type 2 MTDs is the length of the headwall area, as demonstrated in this work (Fig. 12). In addition, variations in slope gradient, and possibly in the volume of material prone to failure, play a secondary role in the development and deformation of the two types of MTDs. Slope angles are consistently higher in evacuation areas of Type 1 MTDs, potentially inducing higher flow velocities (Posamentier and Martinsen, 2011), and thus explaining the significant deformation observed in these regions (Figs. 5 and 10b). In comparison, the moderate deformation and length of Type 2 deposits can be related to lateral dispersion of failure-inducing stresses along a wider area and favour slower, more constrained remobilisations.

Based on the data in this work, Type 1 is the most common on continental margins, correlating with both large slope-attached and detached MTDs (e.g. Moscardelli and Wood, 2008). Type 1 MTDs develop divergent flow patterns if topographically unconfined. In contrast, Type 2 MTDs are less common and prone to prevail in confined basins bound by elongate unstable structures such as salt ridges. They present relatively limited run-out distances, and convergent (this work) or divergent flow patterns (e.g. Posamentier and Martinsen, 2011), depending on the curvature of the flanking structure.

\subsection{Timing of MTDs as indicators of salt deformation}

Discrete failure episodes in salt-withdrawal basins can be associated with specific pulses of salt growth or withdrawal subsidence (Madof et al., 2009). As the Miocene MTDs share the same detachment surface (Fig. 3), it was possible to estimate a relative chronology and spatial order for salt-influenced slope failure in the studied minibasin. Mass-transport deposit A is the oldest massfailure occurring along $\mathrm{H} 1$ as its top is delimited by horizon $\mathrm{H} 3$, while the remaining MTDs are capped by H4 (Fig. 14a). This observation suggests that during the time interval spanning H3 to H4, seafloor deformation occurred in the northern part of the salt minibasin in association with local 
halokinesis. Such a phenomenon had the potential to reactivate large faults underlying MTD A (Fig. 5), inducing localised subsidence and triggering MTDs in the axis of the minibasin (Fig. 14a). PostMTD tectonic pulses were relatively less intense, if at all significant, as no evidence for large remobilisation episodes are observed where horizon H4 overlies MTD A (Fig. 14a). Subsequent tectonic instability of salt ridges R1 and R2 occurred in the southern part of the minibasin, as indicated by MTDs B and C. These two MTDs were triggered at a time when H4 constituted the paleo-seafloor (Fig. 14a).

Finding the time relationships between MTDs can indicate if they occurred at the same time due to subsidence of parts of the minibasin or, instead, if diachronous movements between salt ridges R1 and R2 triggered slope failure. In the studied minibasin, this 4D analysis is difficult to attain on seismic data alone as there is a relative lack of cross-cutting relationships between MTDs, and unambiguous interference between their toe structures (Fig. 4b, and 9d). The flank-derived MTDs are most probably separated by a short time period, but in such a context MTD C is likely to materialise a larger remobilisation event due to its size and the presence of large slow-moving slabs. Nevertheless, the morphology of the seafloor MTDs can be used as a proxy to interpret their relative age as sharper scarps and edges often indicate younger deposits less smoothed by erosion or draping (Tripsanas et al., 2004). The smoother tops of MTDs deposited around ridge R2 suggest these are older events than equivalent deposits flanking R1 (Fig. 14b). However, based on the morphology of seafloor scarps there were recent failure events close to the crest of R2 (Figs. 9). We hypothesise that, in more recent times, there has been relevant salt-induced deformation with major instability episodes initially taking place along ridge R2 and, in a second phase, on the flanks of ridge R1 (Fig. 14b). 


\section{Conclusions}

This paper proposes classifying MTDs in two types, Type 1 and Type 2, based on the quantification of headwall length/distance-to-toe ratios measured for seven distinct MTDs:

a) Type 1 MTDs are defined by headwall length/distance-to-toe ratios below one (1), having their long axis parallel to the direction of movement.

b) Type 2 MTDs show headwall length/distance-to-toe ratios above one (1) and a long axis perpendicular to the runout direction.

c) The deformation styles of MTDs correlate with their types. Type 1 MTDs show intense, but less complex deformation with thinned evacuation domains followed by thickened toe domains with compressional ridges and variable frontal confinement. Type 2 MTDs show marked lateral changes of internal deformation styles.

Of relevance to this work is also the enhanced preservation of strata recorded at the transitional domain of Type 2 MTDs, represented by slabs of coherent strata, when compared to the higher degree of strata disaggregation at source regions. Secondary compressional and extensional domains have been identified in both Type 1 and Type 2 MTDs. The presence of underlying structures, or a combination of variable slope gradients and internal MTD flow velocities, can induce the genesis of these secondary deformation domains.

The morphology of Miocene MTDs suggest that salt movement was initially located on the northern part of the studied salt minibasin. Subsequent halokinetic pulses occurred southwards and caused the slope failures on the salt ridges. Hence, MTDs in salt-withdrawal basins can be used to identify variations in the growth of salt structures in time. 
The MTD classification in this work is valid for both marine and lacustrine settings worldwide, and can be used to predict the deformation character and remobilisation dynamics of these deposits. This is particularly the case for the less common Type 2 MTDs, whose geometry puts in question the published deformation models established for slope failures. The examples in this work highlight the importance of correctly identifying remobilised strata on continental margins. If merely based on individual seismic profiles, slabs can be misinterpreted as unremobilised strata in areas of significant slope movement and deformation.

\section{Acknowledgements}

The authors thank CGG for the permission to publish the data presented in this paper. Schlumberger is acknowledged for the provision of seismic interpretation software. The Sêr Cymru National Research Network for Low Carbon, Energy and Environment (NRN-LCEE) is acknowledged for partial funding that supported this research. Davide Gamboa publishes with the permission of the Executive Director, British Geological Survey. Joana Gafeira is acknowledged for the comments and discussions on earlier versions of this manuscript. We would also like to thank Joshu Mountjoy and an anonymous reviewer for their constructive comments, and Michele Rebesco for the editorial handling of the manuscript.

\section{References}

Alves, T.M., 2015. Submarine slide blocks and associated soft-sediment deformation in deep-water basins: A review. Marine and Petroleum Geology, 67: 262-285.

Alves, T.M. and Cartwright, J.A., 2009. Volume balance of a submarine landslide in the Espírito Santo Basin, offshore Brazil: Quantifying seafloor erosion, sediment accumulation and depletion. Earth and Planetary Science Letters, 288(3-4): 572-580. 
Alves, T.M. and Lourenço, S.D.N., 2010. Geomorphologic features related to gravitational collapse: Submarine landsliding to lateral spreading on a Late Miocene-Quaternary slope (SE Crete, eastern Mediterranean). Geomorphology, 123(1-2): 13-33.

Ashabranner, L.B., Tripsanas, E.K. and Shipp, R.C., 2010. Multi-direction flow in a Mass-Transport Deposit, Santos Basin, offshore Brazil. In: D.C. Mosher et al. (Eds.), Submarine Mass Movements and Their Consequences. Springer, pp. 247-255.

Barker, P.F., Buffler, R.T. and Gambôa, L.A., 1983. A seismic reflection study of the Rio Grande Rise. In: P.F. Barker, R.L. Carlson and D.A. Hohnson (Eds.), Initial Reports of the Deep Sea Drilling Program, Washington, D.C., Government Printing Office, pp. 953-976.

Beaubouef, R.T. and Abreu, V., 2010. MTCs of the Brazos-Trinity Slope System; Thoughts on the Sequence Stratigraphy of MTCs and Their Possible Roles in Shaping Hydrocarbon Traps. In: D.C. Mosher et al. (Eds.), Submarine Mass Movements and Their Consequences. Springer, pp. $475-490$.

Bull, S., Cartwright, J. and Huuse, M., 2009. A review of kinematic indicators from mass-transport complexes using 3D seismic data. Marine and Petroleum Geology, 26(7): 1132-1151.

Butler, R.W.H. and McCaffrey, W.D., 2010. Structural evolution and sediment entrainment in masstransport complexes: outcrop studies from Italy. Journal of the Geological Society, 167(3): 617-631.

Davison, I., 2007. Geology and tectonics of the South Atlantic Brazilian salt basins. In: A.C. Ries, R.W.H. Butler and R.H. Graham (Eds.), Deformation of the Continental Crust: The Legacy of Mike Coward. Geological Society London, Special Publications 272, pp. 345-359.

Davison, I., Alsop, G.I., Evans, N.G. and Safaricz, M., 2000. Overburden deformation patterns and mechanisms of salt diapir penetration in the Central Graben, North Sea. Marine and Petroleum Geology, 17(5): 601-618. 
Demercian, S., Szatmari, P. and Cobbold, P.R., 1993. Style and pattern of salt diapirs due to thinskinned gravitational gliding, Campos and Santos basins, offshore Brazil. Tectonophysics, 228(3-4): 393-433.

Fiduk, J.C., Brush, E.R., Anderson, L.E., Gibbs, P.B. and Rowan, M.G., 2004. Salt deformation, magmatism, and hydrocarbon prospectivity in the Espirito Santo Basin, offshore Brazil. In: P.J. Post et al. (Eds.), Salt-sediment interactions and hydrocarbon prospectivity: Concepts, applications, and case studies for the 21st century. GCSSEPM 24th Annual Research Conference, pp. 370-392.

França, R.L., Del Rey, A.C., Tagliari, C.V., Brandão, J.R. and Fontanelli, P.R., 2007. Bacia de Espírito Santo. Boletim de Geociências da Petrobras, 15(2): 501-509.

Frey-Martinez, J., Cartwright, J. and Hall, B., 2005. 3D seismic interpretation of slump complexes: examples from the continental margin of Israel. Basin Research, 17(1): 83-108.

Frey-Martínez, J., Cartwright, J. and James, D., 2006. Frontally confined versus frontally emergent submarine landslides: A 3D seismic characterisation. Marine and Petroleum Geology, 23(5): 585-604.

Gafeira, J., Long, D., Scrutton, R. and Evans, D., 2010. 3D seismic evidence of internal structure within Tampen Slide deposits on the North Sea Fan: are chaotic deposits that chaotic? Journal of the Geological Society, 167(3): 605-616.

Galloway, W.E., 1998. Siliciclastic slope and base-of-slope depositional systems: component facies, stratigraphic architecture, and classification. AAPG bulletin, 82(4): 569-595.

Gamboa, D., Alves, T. and Cartwright, J., 2011. Distribution and characterization of failed (mega) blocks along salt ridges, southeast Brazil: Implications for vertical fluid flow on continental margins. Journal of Geophysical Research, 116(B8): B08103.

Gamboa, D., Alves, T., Cartwright, J. and Terrinha, P., 2010. MTD distribution on a 'passive' continental margin: The Espírito Santo Basin (SE Brazil) during the Palaeogene. Marine and Petroleum Geology, 27(7): 1311-1324. 
Gamboa, D. and Alves, T.M., 2015. Three-dimensional fault meshes and multi-layer shear in masstransport blocks: Implications for fluid flow on continental margins. Tectonophysics, 647648(0): 21-32.

Gee, M.J.R., Gawthorpe, R.L. and Friedmann, S.J., 2006. Triggering and Evolution of a Giant Submarine Landslide, Offshore Angola, Revealed by 3D Seismic Stratigraphy and Geomorphology. Journal of Sedimentary Research, 76(1): 9-19.

Giles, K.A. and Lawton, T.F., 2002. Halokinetic sequence stratigraphy adjacent to the El Papalote diapir, northeastern Mexico. AAPG bulletin, 86(5): 823-840.

Giles, K.A. and Rowan, M.G., 2012. Concepts in halokinetic-sequence deformation and stratigraphy. In: G.I. Alsop, S.G. Archer, A.J. Hartley, N.T. Grant and R. Hodgkinson (Eds.), Salt Tectonics, Sediments and Prospectivity, Geological Society, London, Special Publications 363, London, pp. 7-31.

Hampton, M.A., Lee, H.J. and Locat, J., 1996. Submarine Landslides. Review of Geophysics, 34(1): 33-59.

Jackson, C.A.-L., 2012. The initiation of submarine slope failure and the emplacement of mass transport complexes in salt-related minibasins: A three-dimensional seismic-reflection case study from the Santos Basin, offshore Brazil. Geological Society of America Bulletin, 124(56): 746-761.

Jackson, M.P.A., Vendeville, B. and Schultz-Ela, D.D., 1994. Structural Dynamics of Salt Systems. Annual Review Of Earth And Planetary Sciences, 22: 93-117.

Klar, A., Aharonov, E., Kalderon-Asael, B. and Katz, O., 2011. Analytical and observational relations between landslide volume and surface area. Journal of Geophysical Research: Earth Surface, 116(F2).

Kvalstad, T.J., Andresen, L., Forsberg, C.F., Berg, K., Bryn, P., Wangen, M., 2005. The Storegga slide: evaluation of triggering sources and slide mechanics. Marine and Petroleum Geology, 22(1-2): 245-256. 
Lee, H.J., 2009. Timing of occurrence of large submarine landslides on the Atlantic Ocean margin. Marine Geology, 264(1-2): 53-64.

Li, W., Alves, T.M., Wu, S., Völker, D., Zhao, F., Mi, L., Kopf, A., 2015. Recurrent slope failure and submarine channel incision as key factors controlling reservoir potential in the South China Sea (Qiongdongnan Basin, South Hainan Island). Marine and Petroleum Geology, 64: 17-30.

Love, F. et al., 2005. Northern Espírito Santo basin canyon models ancient sand transport. Offshore, March 2005: 74-78.

Madof, A.S., Christie-Blick, N. and Anders, M.H., 2009. Stratigraphic controls on a salt-withdrawal intraslope minibasin, north-central Green Canyon, Gulf of Mexico: Implications for misinterpreting sea level change. AAPG bulletin, 93(4): 535-561.

Maia, A., Cartwright, J., Andersen, E. and Gamboa, D., 2015. Fluid flow within MTDs: Evidences of fluid storage and leakage from 3D seismic data, offshore West Africa, 7th International Symposium of Submarine Mass Movements and Their Consequences, Wellington, NZ.

Masson, D.G., Harbitz, C.B., Wynn, R.B., Pedersen, G. and Løvholt, F., 2006. Submarine landslides: Processes, triggers and hazard prediction. Philosophical Transactions: Mathematical, Physical and Engineering Sciences (Series A), 364(1845): 2009-2039.

Micallef, A., Berndt, C., Masson, D.G. and Stow, D.A., 2008. Scale invariant characteristics of the Storegga Slide and implications for large-scale submarine mass movements. Marine Geology, 247(1): 46-60.

Moernaut, J. and De Batist, M., 2011. Frontal emplacement and mobility of sublacustrine landslides: Results from morphometric and seismostratigraphic analysis. Marine Geology, 285(1-4): 2945.

Mohriak, W.U., 1995. Salt tectonics structural styles: contrasts and similarities between the South Atlantic and the Gulf of Mexico. In: C.J. Travis et al. (Eds.), Salt, Sediment and Hydrocarbons, Gulf Coast Section of the Society of Economic Paleontologists and 
Mineralogists ( GCSSEPM Foundation), 16th Annual Research Conference, Houston, Texas, pp. 177-191.

Mohriak, W.U., 2003. Bacias sedimentares da margem continental Brasileira. In: L.A. Bizzi, C. Schobbenhaus, R.M. Vidotti and J.H. Goncalves (Eds.), Geologia, Tectonica e Recursos Minerais do Brasil. CPRM, Brasilia, pp. 87-165.

Moreira, J.L.P. and Carminatti, M., 2004. Sistemas deposicionais de talude e de bacia no Eoceno da Bacia de Santos. Boletim de Geociências da Petrobras, 12(1): 73-87.

Moscardelli, L. and Wood, L., 2008. New classification system for mass transport complexes in offshore Trinidad. Basin Research, 20(1): 73-98.

Moscardelli, L. and Wood, L., 2015. Morphometry of mass-transport deposits as a predictive tool. Geological Society of America Bulletin: B31221. 1.

Nemec, W., 1991. Aspects of sediment movement on steep delta slopes. In: A. Colella and D.B. Prior (Eds.), Coarse-Grained Deltas: International Association of Sedimentologists Special Publication 10, pp. 29-73.

O'Leary, D., 1991. Structure and morphology of submarine slab slides: clues to origin and behavior. Marine Georesources \& Geotechnology, 10(1-2): 53-69.

Ogata, K., Mountjoy, J.J., Pini, G.A., Festa, A. and Tinterri, R., 2014. Shear zone liquefaction in mass transport deposit emplacement: A multi-scale integration of seismic reflection and outcrop data. Marine Geology, 356(0): 50-64.

Olafiranye, K., Jackson, C.A.-L. and Hodgson, D.M., 2013. The role of tectonics and mass-transport complex emplacement on upper slope stratigraphic evolution: A 3D seismic case study from offshore Angola. Marine and Petroleum Geology, 44: 196-216.

Omosanya, K.d.O. and Alves, T.M., 2013a. Ramps and flats of mass-transport deposits (MTDs) as markers of seafloor strain on the flanks of rising diapirs (Espírito Santo Basin, SE Brazil). Marine Geology, 340(0): 82-97. 
Omosanya, K.O. and Alves, T.M., 2013b. A 3-dimensional seismic method to assess the provenance of Mass-Transport Deposits (MTDs) on salt-rich continental slopes (Espírito Santo Basin, SE Brazil). Marine and Petroleum Geology, 44: 223-239.

Posamentier, H. and Martinsen, O.J., 2011. The character and genesis of submarine mass-transport deposits: insights from outcrop and 3D seismic data. In: C. Shipp, P. Weimer and H. Posamentier (Eds.), Mass-transport deposits in deepwater settings. SEPM Special Publication 96, pp. 7-38.

Sultan, N. et al., 2004. Triggering mechanisms of slope instability processes and sediment failures on continental margins: a geotechnical approach. Marine Geology, 213(1-4): 291-321.

Tripsanas, E.K., Bryant, W.R. and Phaneuf, B.A., 2004. Slope-instability processes caused by salt movements in a complex deep-water environment, Bryant Canyon area, northwest Gulf of Mexico. AAPG bulletin, 88(6): 801-823.

Tripsanas, E.K., Piper, D.J.W., Jenner, K.A. and Bryant, W.R., 2008. Submarine mass-transport facies: new perspectives on flow processes from cores on the eastern North American margin. Sedimentology, 55(1): 97-136.

Varnes, D.J., 1978. Slope movement types and processes. Transportation Research Board Special Report(176).

\section{Figures}

Figure 1. a) Location of the Espírito Santo Basin on the SE Brazilian margin. b) Seafloor map of the salt-withdrawal minibasin studied in this paper. Several MTDs occur on the seafloor, around N-trending salt ridges R1 and R2. Small axial MTDs and small extensional faults are also observed in the northern part of the minibasin. c) Stratigraphy of the Espírito Santo Basin highlighting main depositional environments and tectonic phases (modified from França et al., 2007). The red box highlights the stratigraphic interval considered in this work. 
Figure 2. Schematic diagram showing interpreted stratigraphic megasequences in the Espírito Santo Basin and main halokinetic styles. The study area is located in compressional domain. Modified after Fiduk et al. (2004) and Gamboa et al. (2010).

Figure 3. a and b) Uninterpreted and interpreted seismic sections along and across the studied minibasin. Miocene MTDs occur between horizons H1 and H4. Extensional faults prevail in the northern areas of the minibasin, and are relatively scarce to the south. c) 3D fence diagrams highlighting the good continuity of the interpreted horizons in the studied minibasin, within and outside the interpreted MTDs.

Figure 4. a) Thickness map of interval H1-H4. The thickness variations observed on the map are due to the presence of MTDs A to C. b) Variance slice from a depth 16 ms above horizon H1, the basal surface of the Miocene MTDs. The MTDs are evidenced by marked changes in variance within well-delimited areas. c) Variance slice from a depth 16 ms below horizon H1 showing the distribution of faults in the studied minibasin.

Figure 5. a, b and c) Seismic profiles intersecting MTD A, which is bounded by numerous faults. d) 3D surface of horizon H3, the top surface of MTD A. Multiple ridges and faults are observed, with relevance for secondary compressional and extensional domains in the middle part of MTD A.

Figure 6. a) Morphologic profiles of $\mathrm{H} 1$ and $\mathrm{H} 3$. b) Thickness map of MTD A. Strata thickening is here associated with areas of compression at the toe of the MTD. c) Variance slice showing the internal heterogeneity of MTD A, curved faults and ridges. d) RMS 
amplitude map of MTD A. Lower amplitudes predominate in the (thinned) extensional domains and in the western part of the toe region.

Figure 7. a) Seismic profile along MTD B, adjacent to salt ridge R2. Thrust faults and associated compressional ridges are frequent at the front of the deposit, which is confined by a frontal ramp. Seismic reflections are well-preserved in the compressional domain when compared to disrupted areas upslope. b) 3D surface of the top of MTD B. c) Thickness map of MTD B. Localised thickening occurs upslope within the erosive slot. d) Variance slice within MTD B, in which no sharp headwall scarp is observed. e) RMS amplitude map showing amplitude variations that reflect the presence of deformation ridges in MTD B.

Figure 8. Seismic sections imaging MTD C. a) Seismic section parallel to the MTD long axis, and crossing individual slabs relatively undeformed. b) Seismic section showing strata buttressing against an MTD slab, and compressional pop-up blocks at the toe domain. The large slabs show scarce internal deformation. c) Seismic section showing numerous extensional faults on the upper part of MTD C due to retrogressive failure. These faults are followed by a slab and distinct compressional structures downslope. d) Evidence of well-developed compressive ridges in the middle part of MTD C. e) Seismic section showing the headwall of MTD C as being controlled by ridge R1, and thrusts within individual slabs.

Figure 9. a) 3D image of the top surface (H4) of MTD C. b) Profile of the base (H1) and top (H4) horizons of MTD C. The roughness of the top surface results from the MTD's deformation, with smoother morphology on top of slabs and sharp irregularities in evacuation and toe domains. c) Thickness map of MTD C. Uniform thickness patterns occur in transitional domains with large slabs. Marked strata thickening is observed in the compressional domain. 
d) Variance slice within MTD C, 16 ms above the horizon H1. The slabs show low variance identical to unremobilised strata outside MTD C. Compressional ridges are observed at the toe and in the middle part of the MTD. e) RMS amplitude map of MTD C, showing predominantly low amplitudes at the headwall domain.

Figure 10. a) 3D gradient surface of MTD SF1 showing elongated slabs and compressive ridges downslope. An headwall scarp is clearly observed, and is associated with rotational blocks. b) 3D gradient surface of MTDs SF2 and SF3. c) Seismic section across MTD SF1 showing preserved reflections in the slab and imbricated thrusts at the toe. d) Thickness map of SF1, showing similar patterns to MTD C. The slabs show uniform thickness patterns, with thickening occurring along the toe domain. e) Seismic section along SF2. The bulk of SF2 shows internal thrusting delimited by a frontal ramp, followed downslope by a thin emergent lobe. f) Thickness map of SF2 showing relative thickening in the compressional domain and a thinner frontal lobe. $\mathbf{g}$ and $\mathbf{h}$ ) Seismic section and thickness map of SF3 highlighting an internal character similar to SF2.

Figure 11. a) 3D gradient surface of MTD SF4. A complex headwall delimits SF4 upslope, and show two main scarps (2045 m and $2100 \mathrm{~m}$ deep) on the flank of ridge R2. b) Seismic section across SF4. Deformation within SF4 is very moderate in its distal part, being only inferred from subtle changes in thickness and reflection geometry.

Figure 12. Statistical plots highlighting scale-relationships between MTD morphological parameters. a) Ratios between the long and short axes of MTDs. b) Measured values for the long and short MTD axes. c) Relationship between the MTD volume and area. d) Volumes and area of slabs in MTD C, showing a very close relationship between both parameters. e) 
Comparison between the size of the slabs in detached MTDs and blocks in attached MTDs, Espírito Santo Basin. f and g) Plots of headwall length versus area and volume of the studied MTDs. h) MTD scarp length vs. distance-to-toe ratio.

Figure 13. a) Schematic diagram of the internal features interpreted in Type 1 MTDs. Internal deformation is significant in these deposits. b) Schematic diagram of the deformation styles observed in Type 2 MTDs. the diagram highlights the presence of slab with very moderate deformation. HL: Headwall Length, DtT: Distance-to-toe.

Figure 14. Deformation episodes in the studied minibasin, and their relative timings, as indicated by the interpreted MTDs. a) MTDs detaching along horizon H1. 1-Deposition of H1 to H3, no significant instability; 2- Localised subsidence and fault movement. Triggering of MTD A, deforming the paleo-seafloor (H3). 3- Deposition of H4. 4- Instability along salt ridges to the south and triggering of MTDs B and C. b) Modern seafloor MTDs. 1- Instability along R2 and initial movement of SF4; 2- Local instability leading to multiple slope failure on both flanks of R1; 3- Smaller-scale failure along R2, and minor subsidence in the northern axis of the studied minibasin. 


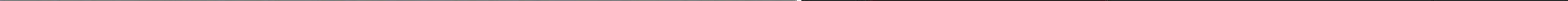




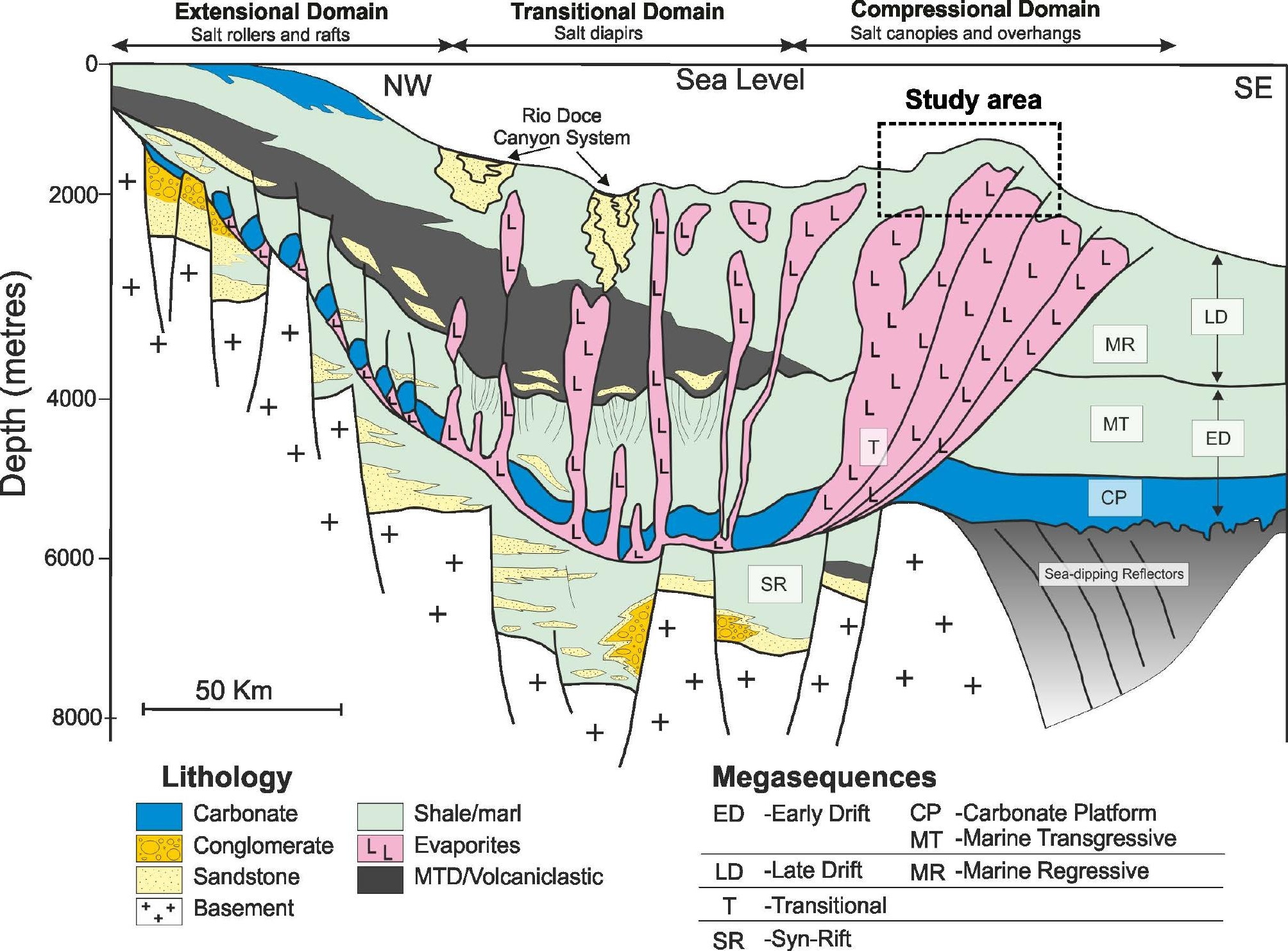




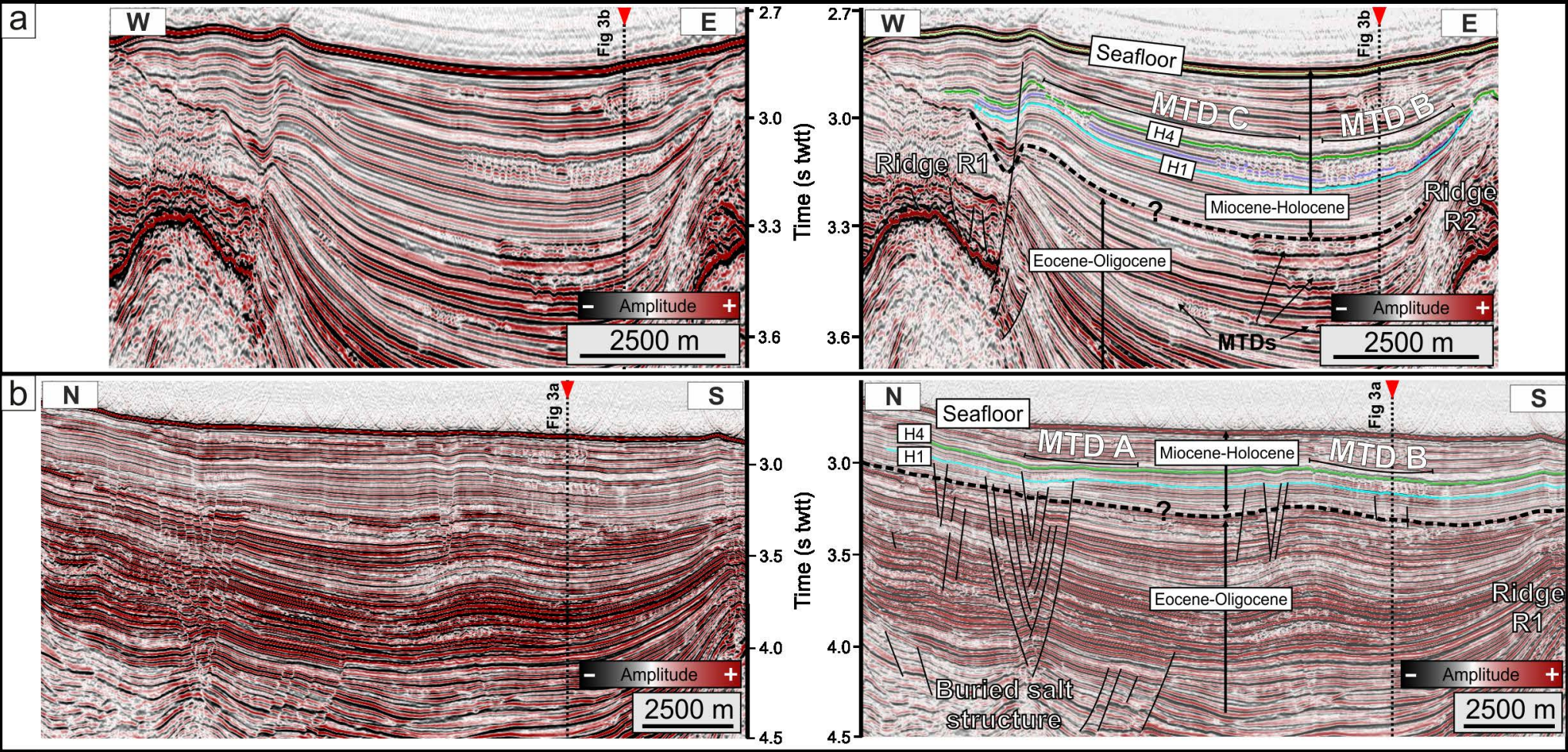
C $\operatorname{DN}^{\mathrm{N}}$
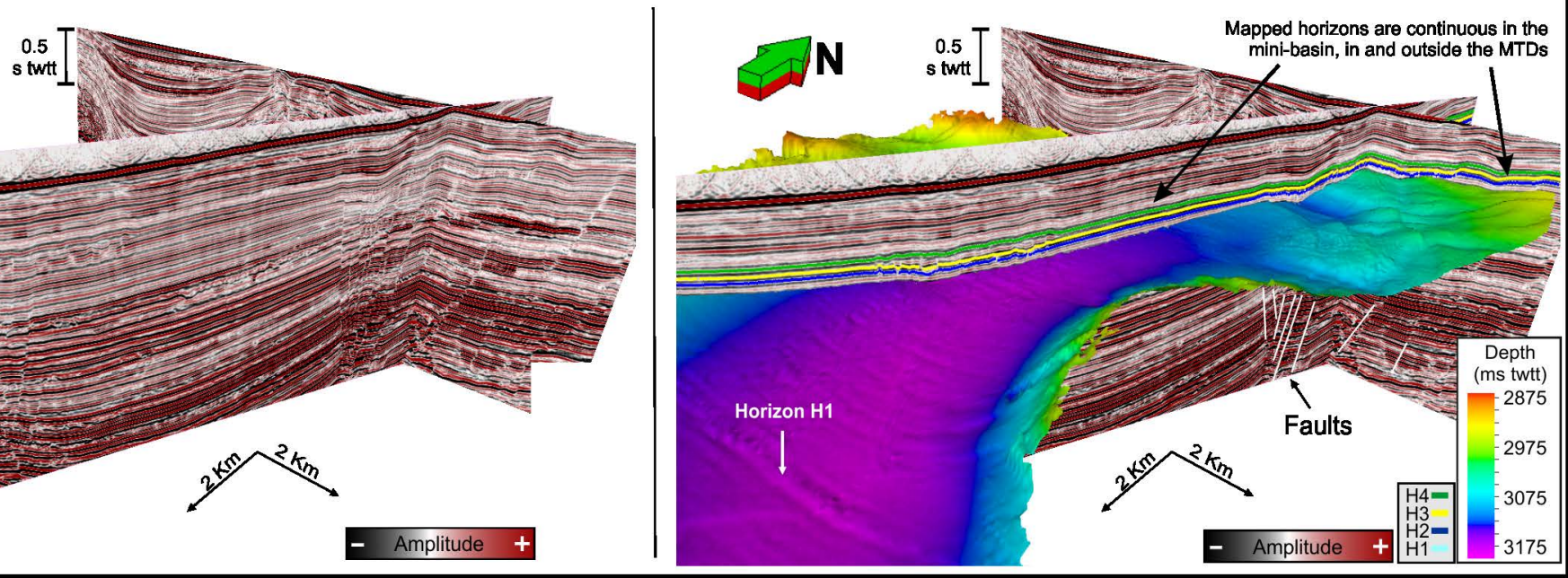


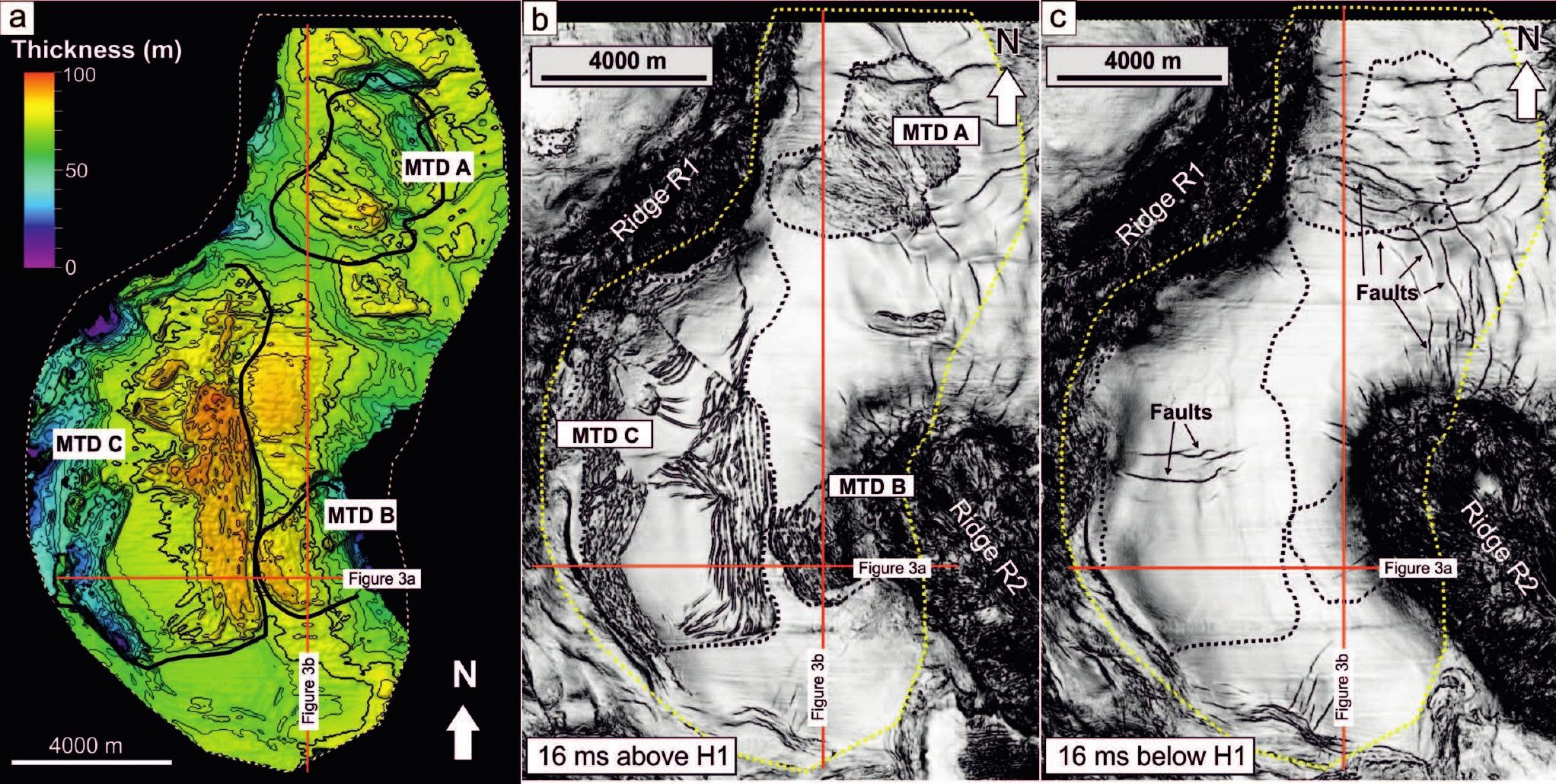



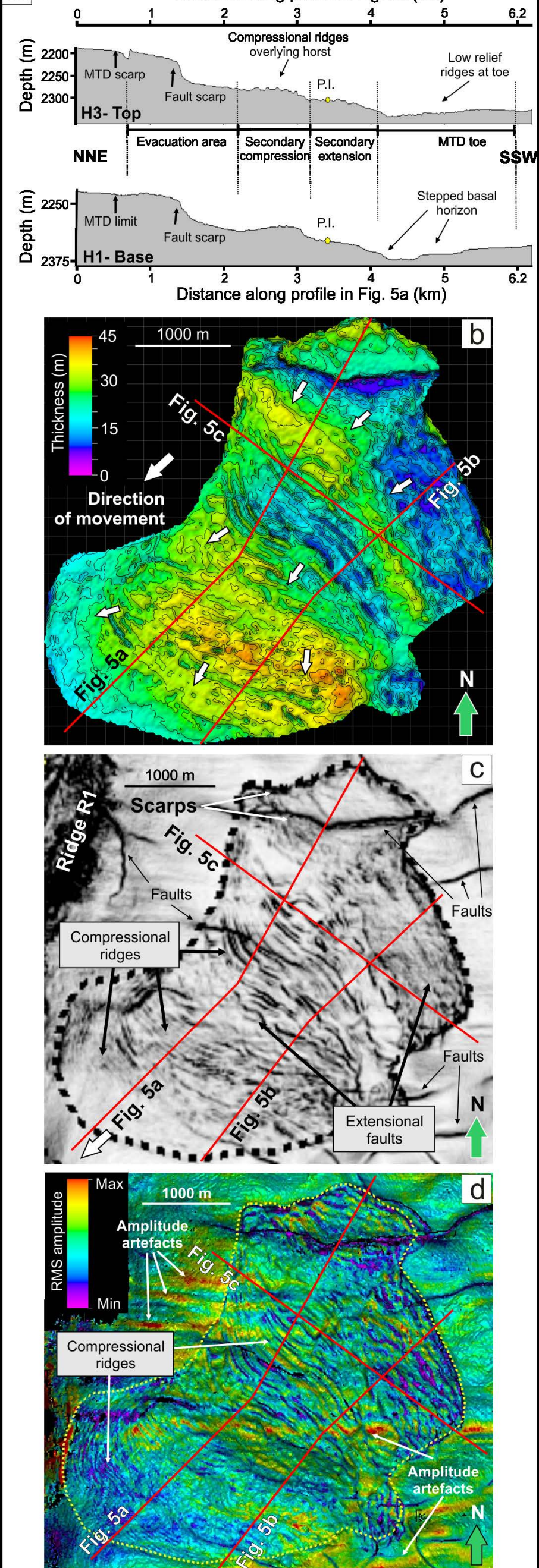


\section{2}




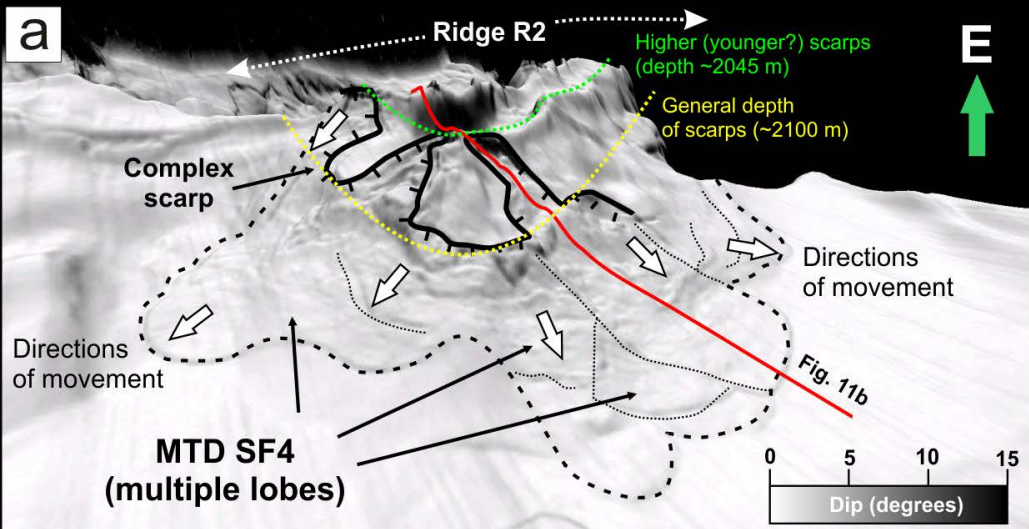

\section{b}

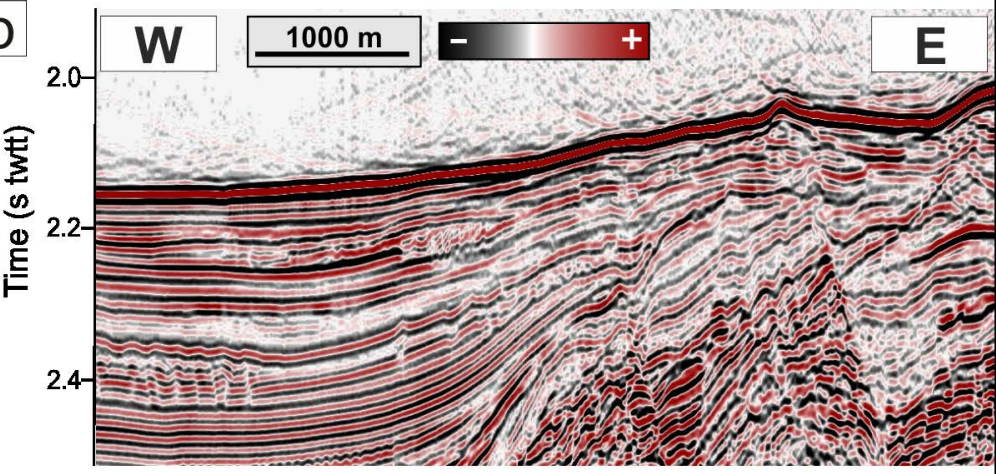

Continuous intra-MTD reflectors

2.0- Distinction from non-MTD strata based on

subtle irregularities and thickness

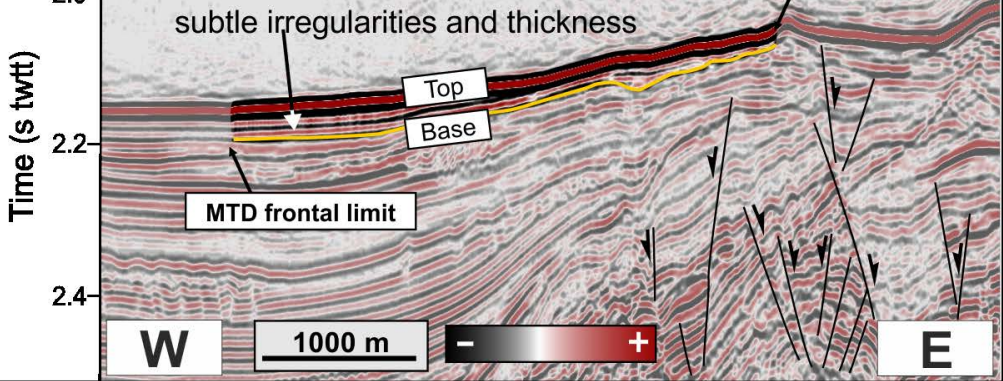




\section{HL / DtT Ratio <1}

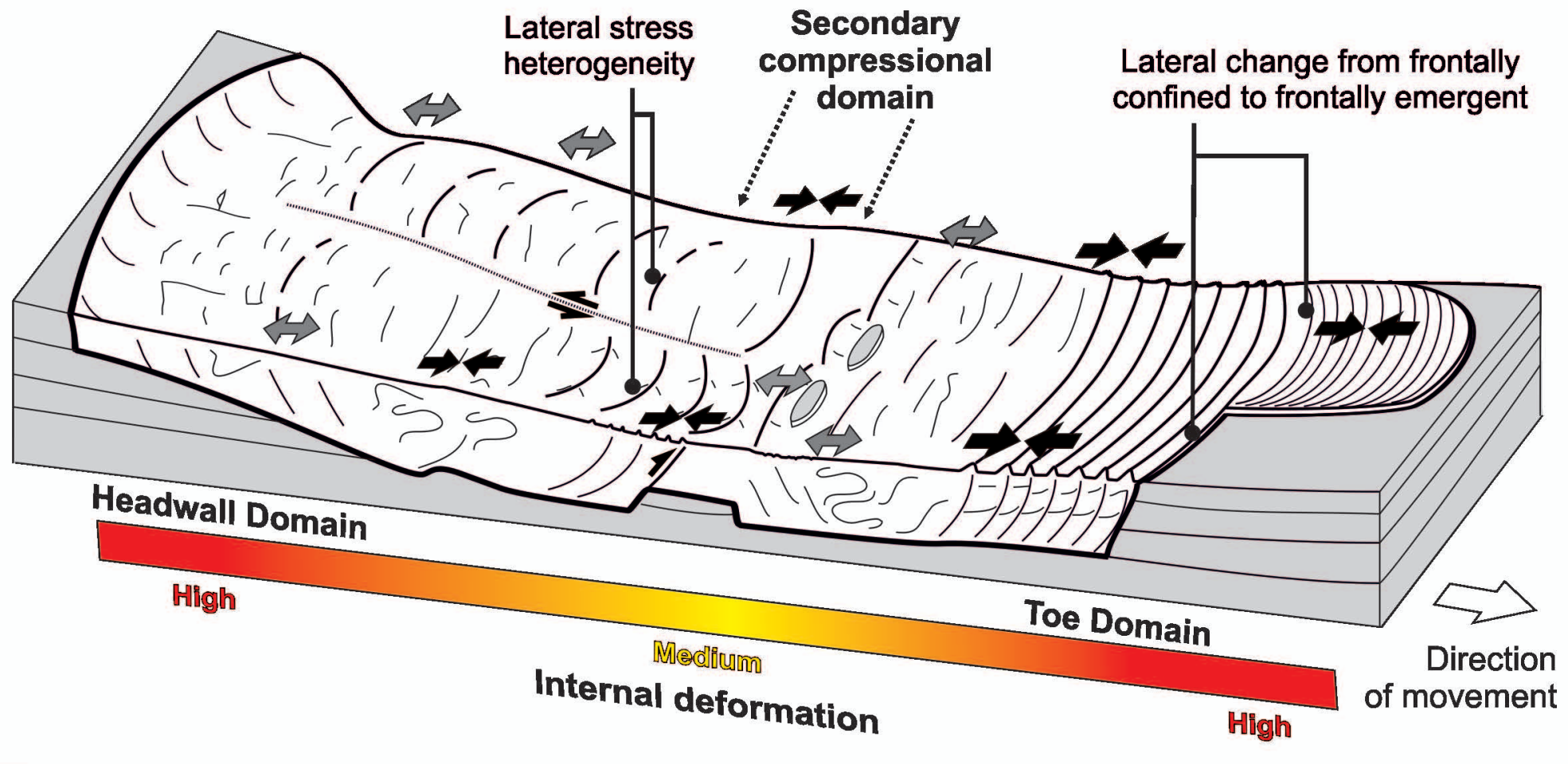

b

Type 2 MTDs

\section{HL / DtT Ratio >1}

4 Extension

$\rightarrow$ Compression $\Rightarrow$ Slab movement

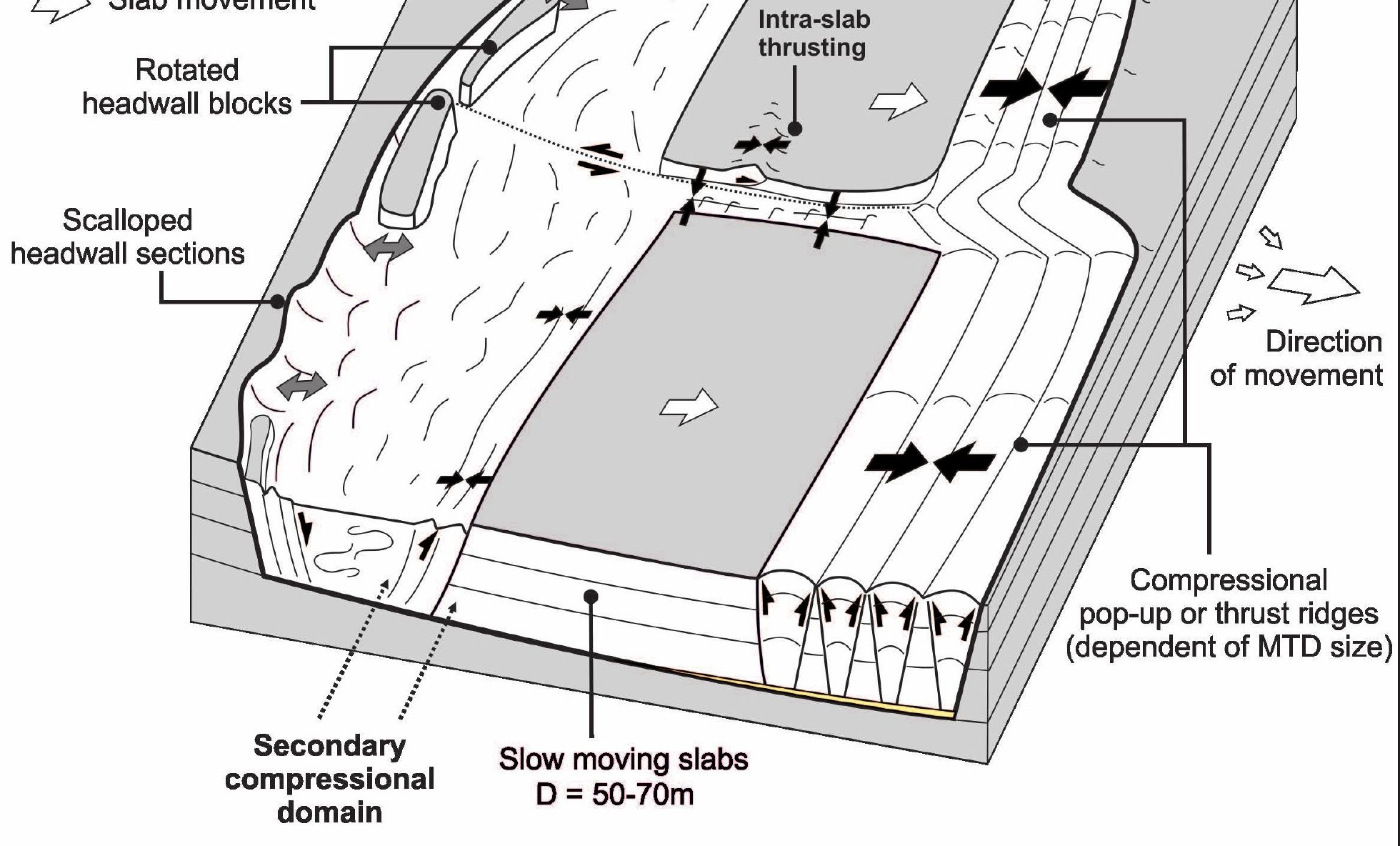




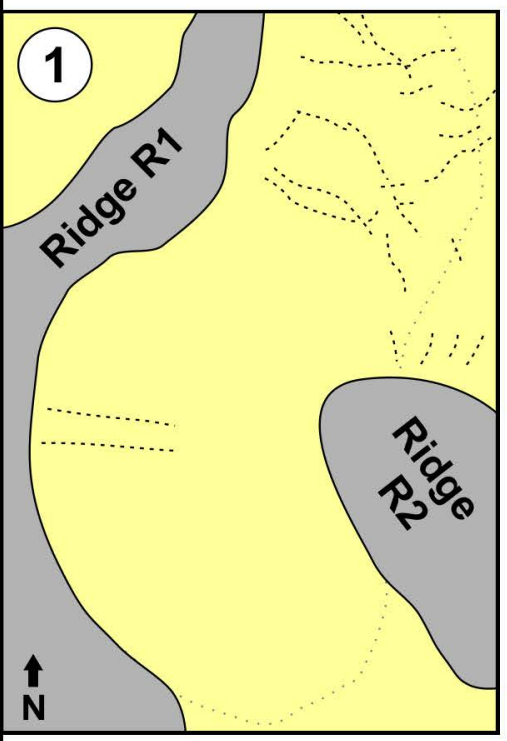

Deposition of $\mathrm{H} 1$ to $\mathrm{H} 3$

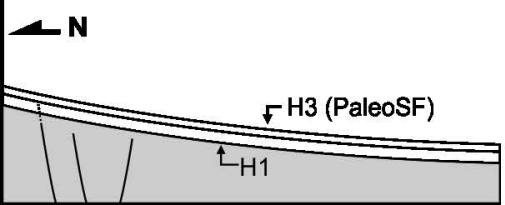

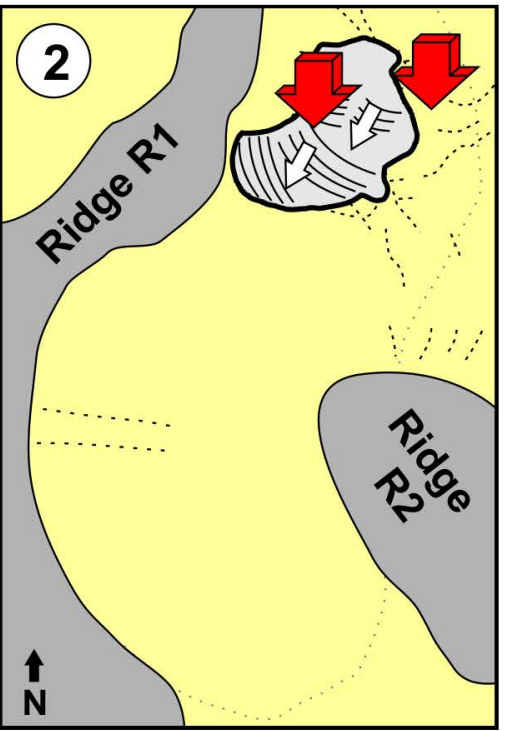

Triggering of MTD A Deformation of $\mathrm{H} 3$ (paleo seafloor)

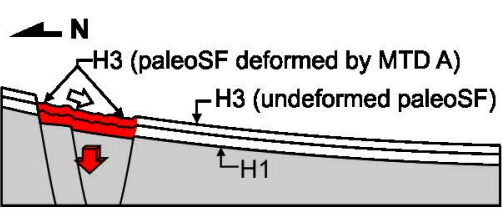

$\Rightarrow$ Movement MTD A

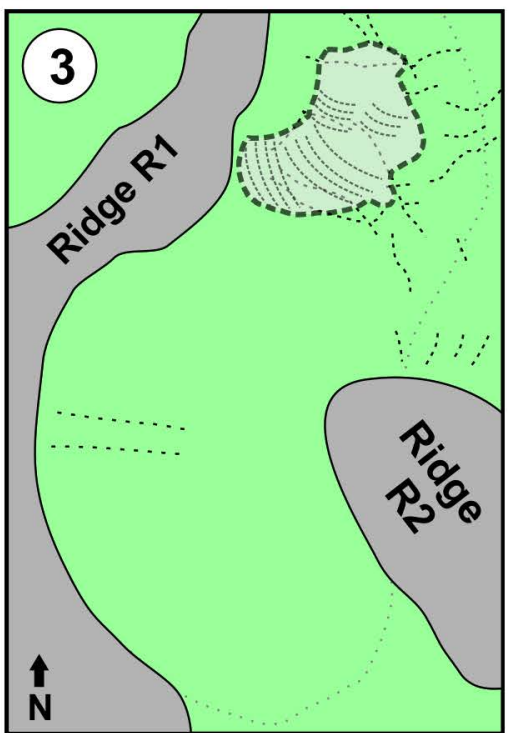

Deposition of $\mathrm{H} 4$

Sediment draping over MTD A

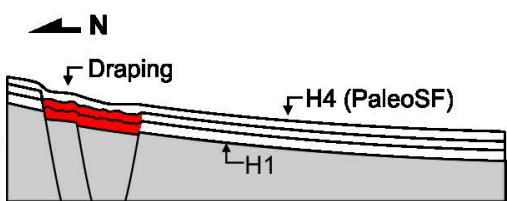

1 Uplift on salt ridges

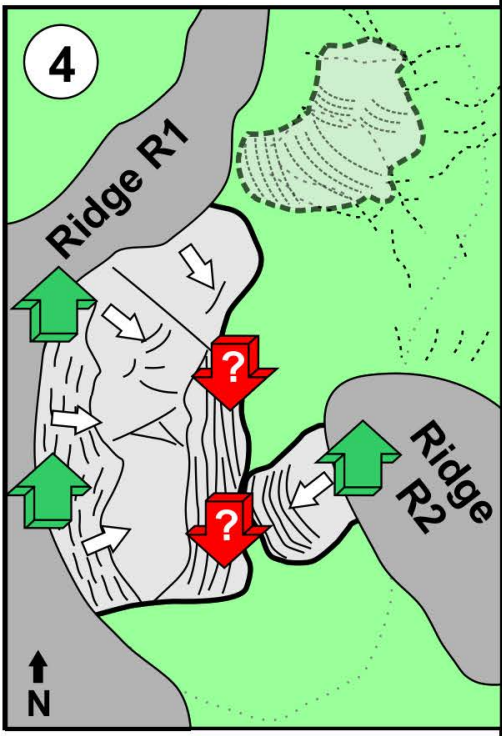

Triggering of MTDs $\mathrm{B}$ and $\mathrm{C}$ Deformation of $\mathrm{H} 4$ by MTDs

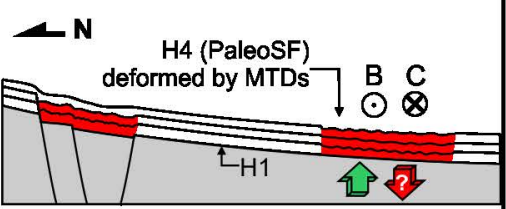

$\bigodot$ Movement MTD B $\bigotimes$ Movement MTD C

Subsidence on basin axis

b Estimated timing of seafloor MTDs

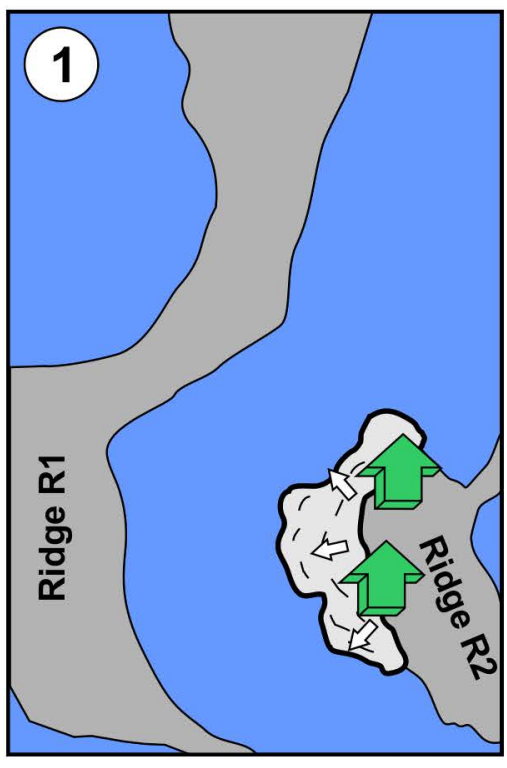

MTDs triggered along Ridge R2

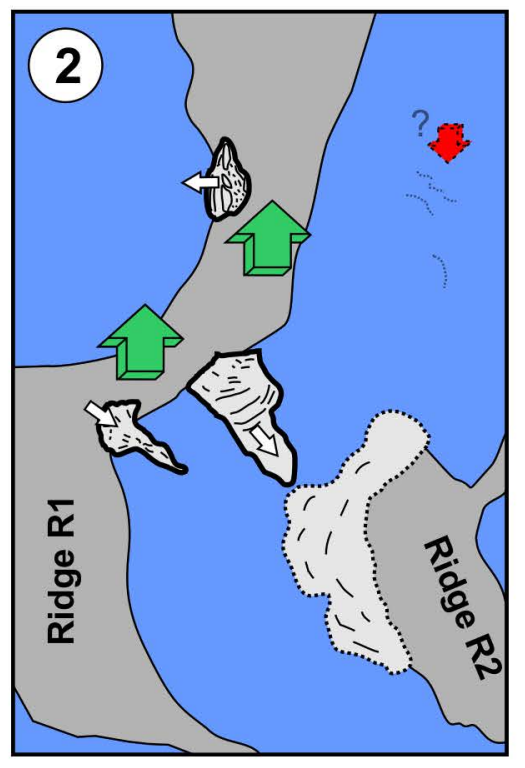

MTDs triggered along Ridge R1

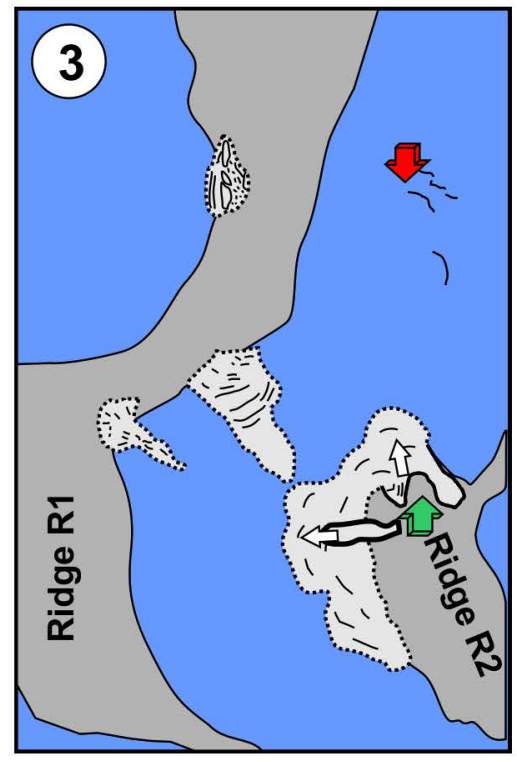

Smaller slope failures on ridge R2 